\title{
Prediction of metabolic and cardiopulmonary responses to maximum cycle ergometry: a randomised study
}

\author{
J.A. Neder*, L.E. Nery* A. Castelo ${ }^{+}$, S. Andreoni", M.C. Lerario ${ }^{\#}$, \\ A. Sachs ${ }^{\#}$, A.C. Silva ${ }^{*}$ B.J. Whipp**
}

Prediction of metabolic and cardiopulmonary responses to maximum cycle ergometry: a randomised study. J.A. Neder, L.E. Nery, A. Castelo, S. Andreoni, M.C. Lerario, A. Sachs, A.C. Silva, B.J. Whipp. C) ERS Journals Ltd 1999.

ABSTRACT: All of the most widely-cited studies for the prediction of maximum exercise responses have utilized either volunteers or referred subjects. Therefore, selection bias, with overestimation of the reference values, is a likely consequence.

In order to establish a set of predictive equations for the gas exchange, ventilatory and cardiovascular responses to maximum ramp-incremental cycle ergometry, this study prospectively evaluated 120 sedentary individuals $(60$ males, 60 females, aged 20-80), randomly-selected from $>\mathbf{8 , 0 0 0}$ subjects. Regular physical activity pattern by questionnaire, body composition by anthropometry and dual energy $X$-ray absorptiometry $(n=75)$ and knee strength by isokinetic dynamometry were also assessed.

Previously reported equations typically overestimated the subjects' peak oxygen uptake $(p<0.05)$. Prediction linear equations for the main variables of clinical interest were established by backward stepwise regression analysis including: sex, age, knee extensor peak torque, bone-free lean leg mass, total and lean body mass, height, and physical activity scores. Reference intervals $(95 \%$ confidence limits) were calculated: some of these values differed markedly from those formerly recommended.

The results therefore might provide a more appropriate frame of reference for interpretation of the responses to symptom-limited ramp incremental cycle ergometry in sedentary subjects; i.e. those usually referred tor clinical cardiopulmonary exercise tests.

Eur Respir J 1999; 14: 1304-1313.

\author{
*Respiratory Division, Dept of Medicine, \\ ${ }^{+}$Multidisciplinary Group of Clinical Epi- \\ demiology (GRIDEC), "\#ept of Prev- \\ entive and Social Medicine, and Dept \\ of Physiology, UNIFESP-EMP, Sao Paulo, \\ Brazil. **Dept of Physiology. St. George's \\ Hospital Medical School; University of \\ London, London, UK. \\ Correspondence: J.A. Neder, Centre for \\ Exercise Science and Medicine, Institute \\ for Biological and Life Sciences, Univ- \\ ersity of Glasgow, West Medical Build- \\ ing, Glasgow, G12 8QQ, UK. Fax: 44 \\ 1413306345 . \\ Keywords: Cycle ergometry, exercise, oxy- \\ gen consumption, reference values \\ Received: September 181998 \\ Accepted after revision May 61999 \\ Partially supported by Research Grants from \\ Fundacas de Amparo a Pesquisa do Estado \\ de Sao Paolo/Conselho Nacional de Des- \\ envolvimento Cientifico e Technologico \\ (FAPESP/CNPq)-Brazil. J.A. Neder was \\ supported by a Post-doctoral Research \\ Fellowship Grant from FAPESP-Brazil (no. \\ 95/9843-0).
}

Cardiopulmonary exercise testing (CPET) is a useful means of objectively assessing the integrated response of the physiological systems of interest to dynamic exercise, usually performed to the limits of tolerance [1]. The appropriateness of these responses, however, require an adequate frame of reference. Without this, the interpretation of exercise studies in subjects who complain of exertional symptoms and work impairment could be hampered and even prone to misinterpretation [2, 3].

Most published reference data obtained on "normal" subjects do not appear to be representative of the sedentary subject typically referred for evaluation. All of the most widely-cited studies, for example, evaluated volunteers and/ or subjects who had been referred for study [4-12]. This is likely to have provided an important source of selection bias as it could be expected that only the more fit subjects would have volunteered: these studies included athletes, students, labourers, servicemen and soldiers [4-12]. Thus, overestimation of the predicted values for the untrained individual is a potential, if not likely, consequence.

Another important pitfall of some previous reports is their retrospective nature, i.e. the use of past data relative to the referred population in which no obvious "abnormality" was apparent $[5,11]$. Additionally, more recent studies have emphasized the importance of total body composition and physical fitness and have incorporated these variables into regression equations $[6,11]$. Nevertheless, other potentially important variable such as leg strength and composition have not been systematically analysed for possible inclusion in these predictive equations.

Therefore, the major purpose of this study was to establish a comprehensive set of predictive equations for the gas exchange, ventilatory and cardiovascular variables during maximum incremental cycle ergometry in a randomized sample of sedentary males and females, aged 20-80 yrs. In addition to the typical demographic and anthropometric variables, this study evaluated the role of leg strength and body and regional composition for the prediction of peak oxygen uptake $\left(V^{\prime} \mathrm{O}_{2}\right)$.

\section{Materials and methods}

\section{Study design and subjects}

This study utilized a random sample of clerical and manual workers from the auxiliary staff of a university centre in a controlled, prospective design. Social, anthropometric and regular physical activity profiles of this sample were shown not to be significantly different from the local general population. Part of the older group (61-80 yrs), however, was obtained from a healthy sedentary general population being followed by the Institutional Geriatric 
Service. No voluntary participation was accepted. This study was conducted over an 18-month period.

The subjects were chosen by random selection, utilizing a standard electronic randomization package, from the total population of 8,226 individuals: these had been previously stratified by sex into 6 age groups (20-29, 30-39, 40-49, $50-59,60-69,70-80 \mathrm{yrs})$; i.e. a total of 12 strata. Ten subjects were studied in each stratum; thus, 120 individuals aged 20-80 yrs were evaluated. This sample size (n) was estimated according to the relationship between the number of variables (v) to be entered into the multiple regression analysis (see Data analysis section) and the minimum, number of observations required: $\mathrm{n}$ was higher than both $\mathrm{v}^{2}$ and $10 \mathrm{v}[13]$.

After the selection, the subjects were contacted and the purpose of the study was explained. If they refused to participate, the authors established the reason(s) for nonacceptance using a questionnaire, which also determined: previous and actual health; leisure and sports habits; and anthropometric measures (height and weight). Thus, care was taken to avoid selection of a population of participants who had a different profile than that of the nonparticipants. A new allotment was always performed if a subject refused participation or if they were excluded (see below); this continued until completion of the desired number of subjects (120) (fig. 1).

Subjects who had a medical history or physical or laboratory findings of cardiac, respiratory, haematological (haemoglobin below $14 \mathrm{dL}^{-1}$ for males and $12 \mathrm{dL}^{-1}$ for females), metabolic or neuromuscular diseases were excluded from the study. Although normal pulmonary function data and absence of respiratory symptoms were required for entry into the study sample, subjects who had current or past history of smoking $<15$ pack-years were not excluded (see Results section). Underweight subjects (body mass index $(\mathrm{BMI})<18.5$ ) or those who were grade III overweight (BMI $>40$ ) [14] were excluded, as were subjects who engaged in intense athletic activity ( $>8 \mathrm{~h} \cdot \mathrm{week}^{-1}$ of activity involving large group muscles). The distribution of reasons for exclusion $(n=213)$ were as follow: systemic arterial hypertension (54), cardiac disease (36), previous severe illness (33), respiratory disease (27), osteomuscular disorder (18), diabetes mellitus (11), use of drugs with potential to influence the exercise responses (8), underweight (7), overweight (11) and athleticism (8). In summary, a total of 333 subjects were evaluated for screening purposes to establish the study group of 120 subjects (fig. 1).

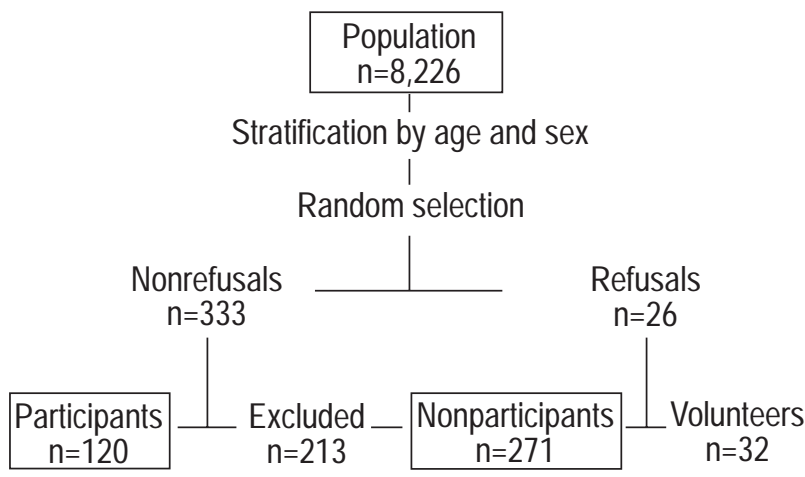

Fig. 1. - The overall study design. Anthropometric and physical activity patterns were also evaluated in the refusals and volunteers.
The self-reported ethnic origin of the subjects was heterogeneous: 43 were Mediterranean, 34 South American, 16 African, 12 North European, seven Slavic, four Japanese, two Arabic and two Chinese. These findings are consistent with the multi-ethnic profile of the urban Southeast Brazilian population. The occupational activity range was also large and similar in both sexes: 51 had sedentary occupations (clerical work or retired), 43 had occupations requiring frequent standing or walking and 26 had an occupation that required manual labour. According to the modified BAECKE et al. [15]. Physical Activity Questionnaire, 102 subjects $(85 \%)$ were considered to be sedentary with a total score $<8$; of these, 70 subjects had scores $6-8$ and 32 had scores $<6$. The remaining 18 subjects $(15 \%)$ had scores $>8$; that is they can be considered to be physically more active but still nontrained subjects. According to the Saltin and Grimby [16] Leisure Time Score, there were 38 subjects in Grade I (exercising $<1$ $\mathrm{h} \cdot$ week $\left.^{-1}\right), 64$ in Grade II $\left(1-3 \mathrm{~h} \cdot\right.$ week $\left.^{-1}\right), 12$ in Grade III $\left(3-6 \mathrm{~h} \cdot \mathrm{week}^{-1}\right)$ and only 6 subjects in Grade IV $(>6$ $\mathrm{h} \cdot \mathrm{week}^{-1}$ ).

\section{Measurements}

Protocol. Briefly, the subjects undertook the following protocol at least $3 \mathrm{~h}$ after the last meal and at least $12 \mathrm{~h}$ after significant exertion or smoking (in the few and light smokers - see Results section): 1) complete clinical, haematological and cardiorespiratory evaluation at rest; 2) evaluation of the regular physical activity pattern by questionnaire $[15,16], 3)$ measurement of total and regional body composition by anthropometry and dual energy Xray absorptiometry $(n=75)[17] ; 4)$ cardiopulmonary exercise tests on a cycle ergometer (a square-wave protocol at $25 \mathrm{~W}$ for subject familiarization and, after $1 \mathrm{~h}$, a maximal ramp-incremental exercise test); 5) on a separate day, a measurement of concentric knee extensor strength by isokinetic dynamometry [18].

Before the tests, the procedures, including the known risks, were described in detail and written, informed consent (as approved by the appropriate Institutional Medical Ethics Committee) was obtained from all subjects. Remuneration was not offered.

Clinical and functional evaluation. A medical history, with previous health information and smoking history, and answers to a questionnaire about respiratory and sleeprelated symptoms were obtained. Complete physical examination and resting 12-lead electrocardiogram were performed by the same physician. Pulmonary function tests (spirometry, 12-s maximal voluntary ventilation, maximal respiratory pressures, static pulmonary volumes by the $\mathrm{N}_{2}$ washout technique and single-breath $\mathrm{CO}$ diffusing capacity) were undertaken in all subjects according to standardized recommendations. [19-22]. Complete blood count and blood chemistry panel were also obtained.

Anthropometry and body composition. Total body mass $(\mathrm{kg})$ was established to the nearest $0.1 \mathrm{~kg}$ using a calibrated balance and body height determined to the nearest 0.5 $\mathrm{cm}$ using a stadiometer; both measurements were performed following the standard techniques with the subjects in light clothes without shoes. Measurements of skinfold 
thickness were made at 4 sites, biceps, triceps, subscapula and iliac-crest, using a skinfold calliper. This provided an estimate of the body subcutaneous fat and lean body mass (LBM) after the method of DURNIN and WOMERSLEY [23]. In a sub-group of individuals $(n=75)$, which was representative of the entire population with regard to sex and age, total and regional (including each leg) bone-free and fat lean masses, and body mineral content were measured using dual energy X-ray absorptiometry (DEXA). The underlying principle of this method is that bone and soft tissue areas can be penetrated by two discrete energy peaks from an X-ray source. The degree of penetration is analysed by a scintillation detector, and dedicated software reconstructs an image of the underlying tissues to give an estimate of their masses (DPX-L; Lumex Inc., Madison, WI, USA) [17]. This method has been shown to be both accurate and reproducible when compared to other standardized techniques [24, 25].

Peripheral muscular strength. Concentric knee extensor strength of the dominant side, expressed as peak torque in Newton-metres (the highest torque value seen from all points in the range of motion), was recorded at velocity of $60^{\circ} \cdot \mathrm{s}^{-1}$ using the isokinetic dynamometer Cybex 6000 (Lumex Inc., Ronkonkoma, NY, USA) [18]. After mild calisthenics and stretching warm up exercise, positioning and stabilization of the subjects were standardized: seated position with the back fully supported and trunk and thigh straps in position. The mechanical axis of rotation of the level arm was aligned to the axis of rotation of the joint being tested. The resistance pad at the end of the level arm was strapped to the most distal part of the tibia. Before testing, while the subject was relaxed, the leg was allowed to fall under gravity over the full range of movement at a standard angular velocity. Angle-specific torque values generated by the passive flexion of the leg and the weight of the level arm were subsequently used by the dynamometer's software to perform the gravity correction over the full range of movement. The subjects were told to perform "as fast as possible" in both directions and this was verbally reinforced using "high-demand" instructions by the same investigator. The dynamometer calibration measurements remained unchanged during the study.

Cardiopulmonary exercise testing. The exercise tests were carried out on an electromagnetically braked cycle ergometer(CPE 2000; Medical Graphics Corp., (MGC), St. Paul, $\mathrm{MN}$, USA) with gas exchange and ventilatory variables being analysed breath-by-breath using a calibrated computer based exercise system (MGC-CPX System; MGC) [26]. Periodically, the overall output data system was validated against a respiratory gas exchange simulator which allows a range of metabolic rates to be established between $0.2-5.0 \mathrm{~L} \cdot \mathrm{min}^{-1}$, with a resulting accuracy of $\pm 2 \%$ [27]. All tests were performed in the same laboratory at an altitude of 680 meters above sea level, barometric pressure of 91.11-92.97 kPa (685-699 $\mathrm{mmHg})$, and temperature controlled between 18-20C (Sao Paulo, Southeast Brazil).

The exercise test consisted of: 1) $2 \mathrm{~min}$ at rest; 2) $3 \mathrm{~min}$ with real "zero" workload, obtained by means of a system which moves the ergometer flywheel at 60 revolutions per minute (rpm); 3) the incremental phase; and 4) a 4 min recovery period. The power (W) was continuously increased in a linear "ramp" pattern $\left(10-25 \mathrm{~W} \cdot \mathrm{min}^{-1}\right.$ in females and $15-30 \mathrm{~W} \cdot \mathrm{min}^{-1}$ in males) so that the incremental exercise test duration was $>8$ and $<12$ min [28]. The subject pedalled to the limit of tolerance with active and standardized encouragement from the same investigator. The following criteria were used to establish a maximum effort: maximum heart rate (HR) $>90 \%$ of age predicted (220 -age), maximum respiratory exchange ratio (R) $>1.20$ or a plateauing of $V^{\prime} \mathrm{O}_{2}$. In those cases where these criteria were not met, the test was repeated within a week. Six subjects did not fulfil the above criteria and were required to repeat the tests.

The data were calculated automatically using standard formulae [29] and displayed in descriptive numerical (average of $15 \mathrm{~s}$ ) and graphical (8 breaths moving average) forms. Correction for the valve dead-space was applied $(115 \mathrm{~mL})$. The following data were obtained breath-bybreath: pulmonary oxygen uptake $\left(V^{\prime} \mathrm{O}_{2}, \mathrm{~mL} \cdot \mathrm{min}^{-1}\right.$ standard temperature and pressure, containing no water vapour (STPD)); pulmonary carbon dioxide production $\left(V^{\prime} \mathrm{CO}_{2}\right.$, $\left.\mathrm{mL} \cdot \mathrm{min}^{-1} \mathrm{STPD}\right)$; R; minute ventilation $\left(V \mathrm{E}, \mathrm{L} \cdot \mathrm{min}^{-1}\right.$ at body temperature and ambient pressure, saturated with water vapour (BTPS)); tidal volume $(V \mathrm{~T}, \mathrm{~mL})$, respiratory rate ( $f$ respirations per minute); ventilatory equivalent for $\mathrm{O}_{2}$ and $\mathrm{CO}_{2}\left(V \mathrm{E} / V^{\prime} \mathrm{O}_{2}\right.$ and $V^{\prime} \mathrm{E} / V^{\prime} \mathrm{CO}_{2}$ respectively); endtidal partial pressures of $\mathrm{O}_{2}$ and $\mathrm{CO}_{2}\left(P \mathrm{ET}, \mathrm{O}_{2}\right.$ and $P \mathrm{ET}, \mathrm{CO}_{2}$, $\mathrm{kPa}(\mathrm{mmHg}))$; $\mathrm{HR}$ beats per minute (bpm) and oxygen pulse $V^{\prime} \mathrm{O}_{2} / \mathrm{HR} \mathrm{mL} \cdot$ beat $\left.^{-1}\right)$.

The average $V^{\prime} \mathrm{O}_{2}$ for the last $15 \mathrm{~s}$ of the ramp was considered to be representative of the subject's peak $V^{\prime} \mathrm{O}_{2}$. The slope of the linear region of the $(\Delta) V^{\prime} \mathrm{O}_{2} / \Delta$ work rate (WR) relationship $\left(\mathrm{mL} \cdot \mathrm{min}^{-1} \cdot \mathrm{W}^{-1}\right)$ was calculated as an index of the efficiency of power generation [29]. The $V^{\prime} \mathrm{O}_{2}$ at the lactate threshold was estimated by the gas exchange threshold (GET) method visually inspecting the inflection point of $V^{\prime} \mathrm{CO}_{2}$ with respect to $V^{\prime} \mathrm{O}_{2}$ (modified V-slope) [30] and by the ventilatory method, when $V \mathrm{E} / V^{\prime} \mathrm{O}_{2}$ and $P$ ET, $\mathrm{O}_{2}$ increased while $V \mathrm{E} / V^{\prime} \mathrm{CO}_{2}$ and $P$ ET, $\mathrm{CO}_{2}$ remained stable [31]. For the accurate determination of the GET, two regions were discarded from the analysis: the initial 2 min in which the slower $V^{\prime} \mathrm{CO}_{2}$ kinetics affect the pulmonary gas exchange relationship and the points beyond the respiratory compensation point. The reading was performed independently by two experienced observers without knowledge of other results or subject identities.

Data analysis. All data obtained were sent to a dedicated data storage system developed for the "CPX Project" (CPX Data). The calculated data were entered into a personal computer for statistical analysis, using the Statistical Package for the Social Sciences (SPSS) (Version 6.20.1; SPSS Inc., Chicago, IL, USA). Means and (SD) were obtained for values in subjects grouped according to sex and age. Analysis of variance (ANOVA) was used to determine differences in the exercise values among groups. If a significant F-ratio was obtained, then the post hoc comparisons were completed using Neuman-Keuls tests. The sex-grouped descriptive data and the differences between predicted and observed peak $V^{\prime} \mathrm{O}_{2}$ values were compared using nonpaired and paired Student's t-test, respectively. Simple correlational (Pearson) and bivaried regression analysis were used to evaluate associations between variables. The probability of a Type I error was established at 0.05 for all tests. 
Backward stepwise multiple linear regression was performed by the technique of least squares minimization with inclusion of exercise responses as dependent variables and demographic, anthropometric, body composition, leg strength and their interactions with sex (assuming sex as the "dummy variable"), as independent variables $(n=120)$. The removal procedure was carried out based on the minimum probability of a P-to-remove value of 0.05 for the variables and 0.01 for the interaction terms. A similar procedure was separately carried out for both sexes $(n=60)$. For all data the coefficient of determination $\left(\mathrm{R}^{2}\right)$ is reported with the standard error of the estimate (SEE, i.e. the square root of the residual sum of squares/N- $p-1$, where $p$ is the number of predictors). After the determination of regression equations, an investigation of possible violations of the normal model was performed with analysis of the studentized residuals (SRED). The presence of possible influential points was analysed by comparing the SRED when a suspected case was or was not included in the equation. Multi-colinearity among independent variables was investigated by examining: 1) the level of tolerance of each variable and the related inflation factor; 2) the eigen values of the scaled, uncentred cross-products matrix [32].

As there is an intrinsic dependence of the residuals in a regression equation which tends to induce an optimistic estimate of both $\mathrm{R}$ and SEE values, the predicted residual sum of squares method (PRESS) was used, because it produces residuals that are independent and, therefore, suitable for cross-validation [33]. In this method, a residual is calculated for each subject by developing an equation with the data of all the other individuals and then predicting the value for the "missed" subject. subsequently, the measured value of that subject is subtracted from the predicted value of the equation. Once the $\mathrm{R}$ and SEE values after the PRESS method are similar to the previous ones, this suggests that the equations could be used on other similar samples without a significant loss in accuracy and predictive power [33].

\section{Results}

\section{Sample characteristics}

As described in the Material and methods section and shown in the figure 1 , the overall population could be separated into three samples: allotted subjects who had agreed to participate and had not been excluded for
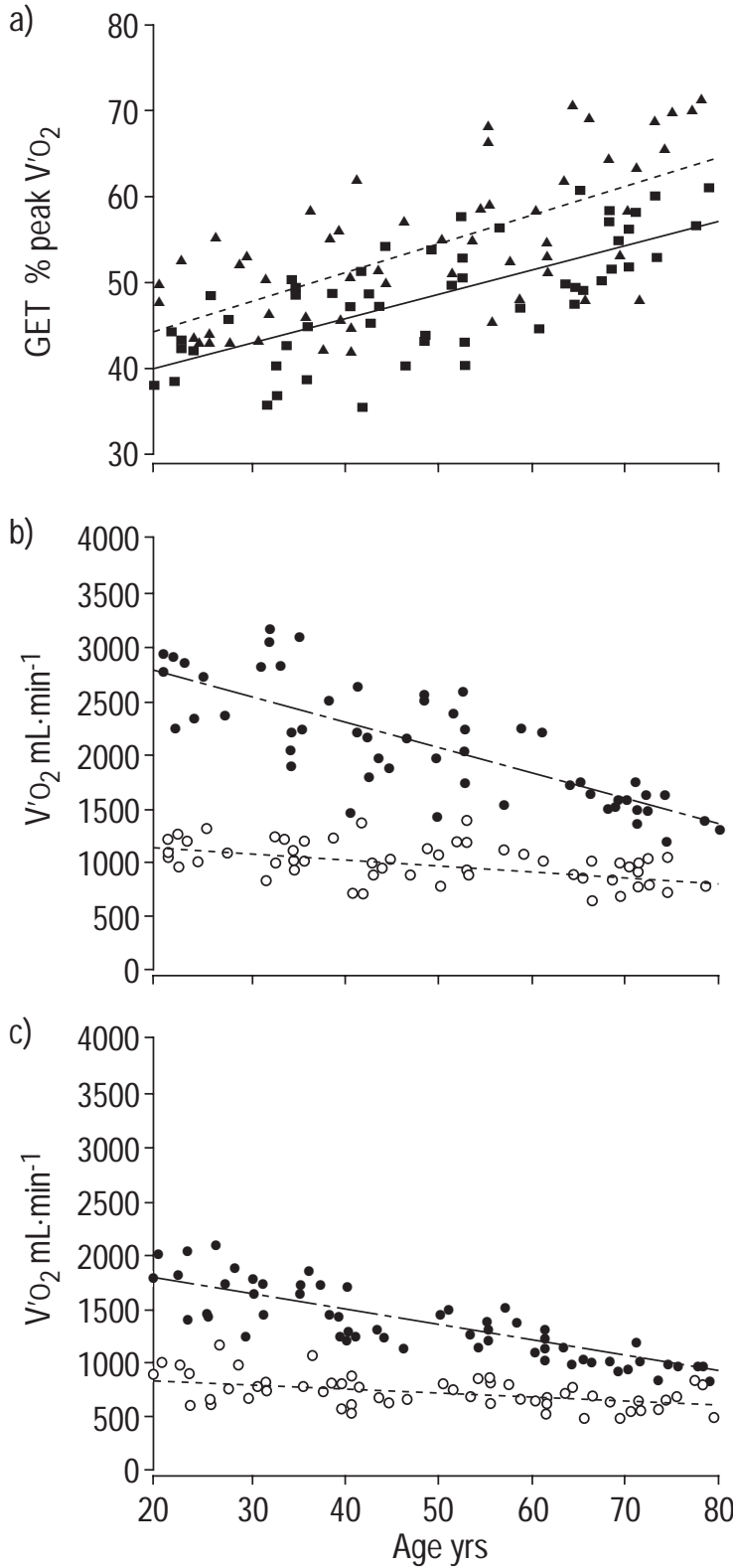

Fig. 2. - a) The gas exchange threshold (GET) was higher in females $\left(\boldsymbol{\Delta} ; \mathrm{R}^{2}=0.4941\right)$ and increased linearly with age in both sexes ( $\boldsymbol{\square}$ : males; $\mathrm{R}^{2}: 0.5622$ ). This occurred due to a progressive reduction in the GET (O) to peak oxygen consumption $\left(V^{\prime} \mathrm{O}_{2}\right)(\mathrm{O})$ difference with age, less in males (b) than females (c).

Table 1. - Anthropometric characteristics for males and females by age groups

\begin{tabular}{|c|c|c|c|c|c|c|c|c|c|c|}
\hline \multirow[b]{2}{*}{$\begin{array}{l}\text { Age } \\
\text { yrs }\end{array}$} & \multicolumn{5}{|c|}{ Males $\mathrm{n}=60^{*}$} & \multicolumn{5}{|c|}{ Females $n=60^{*}$} \\
\hline & $\begin{array}{l}\text { Height } \\
\mathrm{cm}\end{array}$ & $\begin{array}{l}\text { Weight } \\
\text { kg }\end{array}$ & $\begin{array}{c}\mathrm{BMI} \\
\mathrm{kg} \cdot \mathrm{m}^{-2}\end{array}$ & $\begin{array}{l}\text { Percentage } \\
\text { fat body } \\
\text { mass }\end{array}$ & $\begin{array}{l}\text { Percentage } \\
\text { fat leg mass }\end{array}$ & $\begin{array}{l}\text { Height } \\
\mathrm{cm}\end{array}$ & $\begin{array}{l}\text { Weight } \\
\text { kg }\end{array}$ & $\begin{array}{c}\mathrm{BMI} \\
\mathrm{kg} \cdot \mathrm{m}^{-2}\end{array}$ & $\begin{array}{c}\text { Percentage } \\
\text { fat body } \\
\text { mass }\end{array}$ & $\begin{array}{c}\text { Percentage } \\
\text { fat leg } \\
\text { mass }\end{array}$ \\
\hline $20-29$ & $170.9 \pm 2.9^{\#}$ & $69.0 \pm 7.7^{\#}$ & $24.1 \pm 3.4$ & $19.3 \pm 3.3^{\S \#}$ & & $159.4 \pm 7.2$ & $62.0 \pm 12.5$ & $24.3 \pm 4.2$ & $28.8 \pm 7.2^{\S}$ & $29.4 \pm 5.9^{\S}$ \\
\hline $30-39$ & $171.4 \pm 7.3^{\#}$ & $76.7 \pm 1.9^{\#}$ & $26.0 \pm 3.4$ & $23.0 \pm 4.1^{\#}$ & $2.8 \pm 5$ & $161.2 \pm 6.3$ & $65.8 \pm 15.3$ & $29.3 \pm 13.9$ & $32.3 \pm 5.4$ & $30.1 \pm 3.4$ \\
\hline $40-49$ & $168.5 \pm 7.7^{\#}$ & $76.0 \pm 8.2^{\#}$ & $26.6 \pm 4.9$ & $25.5 \pm 8.4^{\#}$ & $21.7 \pm 6.8$ & $157.1 \pm 4.8$ & $60.6 \pm 12.9$ & $24.4 \pm 3.7$ & $35.0 \pm 4.3$ & $32.8 \pm 2.0$ \\
\hline $50-59$ & $164.4 \pm 5.6^{\#}$ & $77.9 \pm 3.1^{\#}$ & $28.9 \pm 5.5$ & $29.6 \pm 3.0^{\#}$ & $19.8 \pm 5.6$ & $156.8 \pm 6.9$ & $66.2 \pm 8.2$ & $27.0 \pm 4.0$ & $39.7 \pm 4.1$ & $36.6 \pm 5.2$ \\
\hline $60-69$ & $167.5 \pm 6.2^{\#}$ & $77.5 \pm 5.9^{\#}$ & $27.6 \pm 2.3$ & $30.4 \pm 4.0^{\#}$ & $20.9 \pm 2.9$ & $155.9 \pm 5.4$ & & $25.5 \pm 3.2$ & $38.4 \pm 3.8$ & $34.5 \pm 1.6$ \\
\hline $70-80$ & $167.3 \pm 7.0^{\#}$ & $70.0 \pm 9.5^{\#}$ & $25.1 \pm 3.9$ & $26.9 \pm 3.8^{\#}$ & $20.5 \pm 5.2$ & $154.4 \pm 7.6$ & $63.2 \pm 9.8$ & $26.5 \pm 3.8$ & $38.6 \pm 5.0$ & $38.1 \pm 2.3$ \\
\hline
\end{tabular}

Data are presented as mean \pm SD. *: ten subjects in each age group; ${ }^{*}$ : measured by dual energy X-ray absorptiometry [17]; ${ }^{*}$ : significant effect between sex groups $(\mathrm{p}<0.01)$. Males versus females by age-group; ${ }^{\S}$ : significant effect among age groups within sex $(\mathrm{p}<0.01) .20-29$ age group versus $50-59$ to $70-80$ groups. BMI: body mass index. 
Table 2. - Oxygen uptake at maximum symptom-limited cycle ergometry (peak oxygen uptake, $\mathrm{mL} \cdot \mathrm{min}^{-1}$ ): linear prediction equations for sedentary males (M) and females (F)

\begin{tabular}{|c|c|c|c|c|c|c|c|c|c|c|c|}
\hline & Equation & $\begin{array}{l}\text { Age } \\
\text { yrs }\end{array}$ & $\begin{array}{l}\text { Weight } \\
\text { kg }\end{array}$ & $\begin{array}{l}\text { Height } \\
\mathrm{cm}\end{array}$ & $\begin{array}{c}\text { Physical } \\
\text { activity score* }\end{array}$ & $\begin{array}{l}\text { Leisure } \\
\text { time score }\end{array}$ & $\begin{array}{l}\text { Lean body } \\
\text { mass } \mathrm{kg}^{\mathrm{f}}\end{array}$ & Constant & $\mathrm{R}^{2}$ & SEE & $\begin{array}{l}\text { Lower } \\
95 \% \text { CL }\end{array}$ \\
\hline \multirow[t]{4}{*}{1} & A M & -24.3 & 12.5 & 9.8 & & & & 702 & 0.755 & 270 & 442 \\
\hline & B F & -13.7 & 7.5 & 7.4 & & & & 372 & 0.812 & 136 & 223 \\
\hline & C Both & $-24.3(\mathrm{M})$ & 10.2 & 8.3 & & & & $1125(\mathrm{M})$ & 0.865 & 214 & 351 \\
\hline & & $-13.7(\mathrm{~F})$ & & & & & & $60(\mathrm{~F})$ & & & \\
\hline \multirow[t]{4}{*}{2} & A M & -22.8 & & 17.9 & & & & 207 & 0.687 & 302 & 495 \\
\hline & B F & -12.7 & & 13.6 & & & & -170 & 0.754 & 155 & 254 \\
\hline & C Both & $-23.0(\mathrm{M})$ & & 15.8 & & & & $570(\mathrm{M})$ & 0.830 & 239 & 392 \\
\hline & & $-12.5(\mathrm{~F})$ & & & & & & $-527(\mathrm{~F})$ & & & \\
\hline \multirow[t]{4}{*}{3} & A M & -25.2 & 14.3 & & & & & 2267 & 0.742 & 274 & 449 \\
\hline & B F & -14.7 & 9.5 & & & & & 1470 & 0.794 & 141 & 231 \\
\hline & C Both & $-25.1(\mathrm{M})$ & 12.1 & & & & & $2431(\mathrm{M})$ & 0.858 & 219 & 359 \\
\hline & & $-14.7(\mathrm{~F})$ & & & & & & $1310(\mathrm{~F})$ & & & \\
\hline \multirow[t]{4}{*}{4} & A M & -22.8 & 12.9 & 6.2 & 132.2 & & & 289 & 0.818 & 235 & 385 \\
\hline & B F & -12.5 & 6.4 & 5.9 & 72.5 & & & 164 & 0.858 & 120 & 196 \\
\hline & C Both & $-23.1(\mathrm{M})$ & $12.9(\mathrm{M})$ & 6.1 & 105.8 & & & $495(\mathrm{M})$ & 0.899 & 187 & 306 \\
\hline & & $-11.9(\mathrm{~F})$ & $5.7(\mathrm{~F})$ & & & & & $-64(\mathrm{~F})$ & & & \\
\hline \multirow[t]{3}{*}{5} & A M & -24.5 & 14.3 & 4.9 & & 197.1 & & 1113 & 0.796 & 249 & 408 \\
\hline & B F & -14.5 & 8.3 & 5.4 & & 103.2 & & 535 & 0.843 & 126 & 206 \\
\hline & C Both & $\begin{array}{l}-24.3(\mathrm{M}) \\
-14.9(\mathrm{~F})\end{array}$ & 11.5 & 4.9 & & 151.8 & & $\begin{array}{c}1398(\mathrm{M}) \\
351(\mathrm{~F})\end{array}$ & 0.885 & 199 & 326 \\
\hline \multirow[t]{3}{*}{6} & A M & -20.5 & & - & 132.0 & & 22.8 & 930 & 0.801 & 243 & 398 \\
\hline & B F & -11.0 & & - & 67.4 & & 18.9 & 694 & 0.881 & 108 & 177 \\
\hline & C Both & $\begin{array}{l}-21.1(\mathrm{M}) \\
-10.1(\mathrm{~F})\end{array}$ & & - & 101.6 & & 20.8 & $\begin{array}{r}1285(\mathrm{M}) \\
363(\mathrm{~F})\end{array}$ & 0.889 & 190 & 311 \\
\hline \multirow[t]{4}{*}{7} & A M & -21.5 & & - & & 156.8 & 25.9 & 1548 & 0.801 & 243 & 398 \\
\hline & B F & -12.3 & & - & & 53.2 & 21.4 & 1029 & 0.870 & 113 & 185 \\
\hline & C Both & $-22.0(\mathrm{M})$ & & - & & 148.3 & 23.5 & $1680(\mathrm{M})$ & 0.885 & 198 & 324 \\
\hline & & $-12.4(\mathrm{~F})$ & & & & & & $783(\mathrm{~F})$ & & & \\
\hline
\end{tabular}

SEE: standard error of the estimate; CL: confidence limit (estimated as $1.64 \times \mathrm{SEE})$; -: the variable was considered in the analysis but had no significant effect on the prediction $(\mathrm{p}>0.05)$. Equations $A$ and $B$ were developed separately by sex $(n=60)$; in the equations $C$ sex was assumed as a dummy variable. *: sum of scores by questionnaire [15]; ${ }^{\#}$ : I to IV weekly leisure time score [16]; ${ }^{*}$ : estimated by skinfold measurement [23]. Blank spaces indicate that the variable was not considered in the regression.

medical reasons (studied "participants", $\mathrm{n}=120$ ), allotted subjects who had not agreed to participate ("refusals", $\mathrm{n}=26$ ) and a group of nonallotted subjects who had volunteered (nonaccepted "volunteers", $n=32$ ). Demographic, anthropometric and physical activity patterns were not different between "participants" and "refusals". On the other hand, important differences were observed between "volunteers" and "participants": volunteers were physically more active (physical activity score $=8.2 \pm 1.3$ versus $6.7 \pm 1.0)$, leaner (BMI=21.9 \pm 3.4 versus $26.3 \pm 5.5 \mathrm{~kg} \cdot \mathrm{m}^{-2}$ ) and younger ( $32.1 \pm 7.5$ versus $49.2 \pm 17.5 \mathrm{yrs}) \mathrm{p}<0.01$.

Anthropometric characteristics for both sexes are presented in table 1, females were shorter and fatter than males for all age decades $(\mathrm{p}<0.01)$. For both sexes there were a progressive trend to gain body mass as fat until the 50 's; after that, a stabilization of percentage fat was observed. However, a similar age-related increase in percentage fat of the legs was found only in the female group (table 1).

\section{Prediction of gas exchange variables}

Data were pooled only after certification of no signinificant effect of ethnicity on exercise variables (i.e. values did not differ significantly among subjects with North European, African or Asiatic heritage). Similarly, the light smoking habit of the sample $(\mathrm{n}=15 ;<10$ pack-years=
$10 ; 10-15$ pack-years $=5$ ) had no significant effect on the maximum or sub-maximal exercise variables.

As expected, age had an important role in the absolute age-related decline in the peak $V^{\prime} \mathrm{O}_{2}$ (fig. 2). This reduction was larger for males than females $\left(0.28 \mathrm{~mL} \cdot \mathrm{kg}^{-1}\right.$. $\mathrm{min}^{-1} \cdot \mathrm{yr}^{-1}$ or $19.3 \mathrm{~mL} \cdot \mathrm{min}^{-1} \cdot \mathrm{yr}^{-1}$ against $0.21 \mathrm{~mL} \cdot \mathrm{kg}^{-1}$. $\min ^{-1} \cdot \mathrm{yr}^{-1}$ or $\left.12.6 \mathrm{~mL} \cdot \mathrm{min}^{-1} \cdot \mathrm{yr}^{-1}\right)$; however the per centexpressed yearly decline was similar between sexes $(0.93$ and $0.94 \%$, respectively). Indeed, age was the most strongly correlated variable in both males and females $(\mathrm{r}=-0.80$ and -0.81 , respectively) followed by knee extensor peak torque (0.66 and 0.82 ), bone-free lean leg mass (0.47 and 0.75$)$, lean body mass $(0.44$ and 0.65$)$, height $(0.38$ and 0.53$)$ and weight $(0.30$ and 0.34$) \mathrm{p}<0.001$. The regression equations for the peak $V^{\prime} \mathrm{O}_{2}$ prediction are presented. in table 2. Given that all of these predictor variables might not be available to an investigator, the authors chose to present a variety of regression equations from several combinations in which the procedures to obtain the independent variables increased in complexity. Equations 1, 2 and 3 were established by using only anthropometric variables; in equations 4 and 5 measurements of level of regular activity $[15,16]$ and, in equations 6 and 7, estimations of lean body mass were included [19]. In summary, although the more complex equations did not improve the adjusted $\mathrm{R}^{2}$ significantly, the dispersion of residuals was narrowed with the use of equations 4-7. 
a)

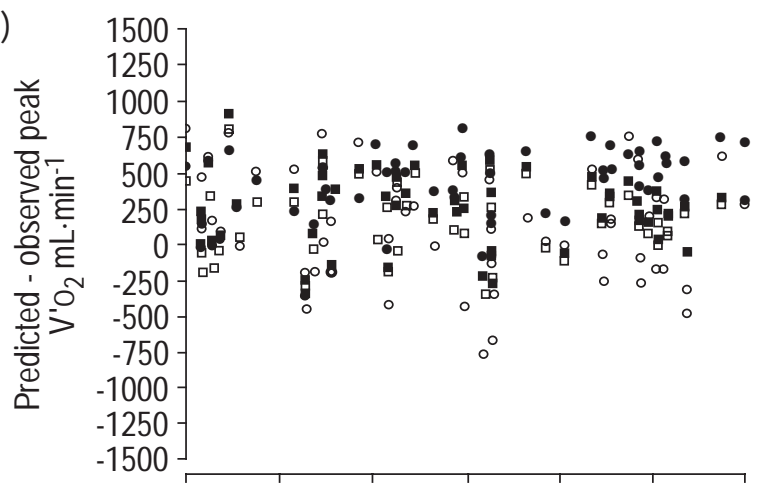

b)

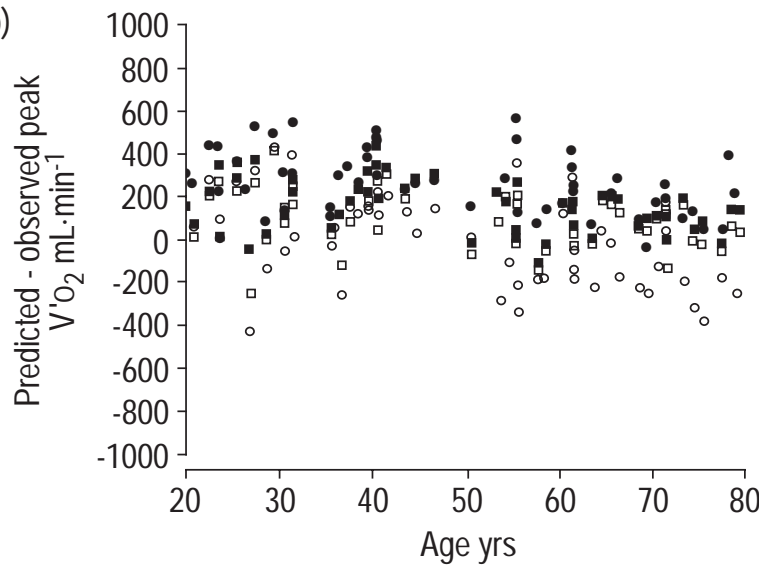

Fig. 3. - Comparison between observed peak oxygen consumption $\left(V^{\prime} \mathrm{O}_{2}\right)$ in the sample and their predicted values by the most cited reference equations in males (a) and females (b). All formulations have considered sex, age, weight and height. $\square$ : Ref. [5]; $\bigcirc$ : Ref. [6]; ○: Ref. [9]; $\square$ : Ref. [29]. Note that except for Ref. [6] the equations overestimated the observed values $(\mathrm{p}<0.05)$ but the equations for Ref. [6] underestimated them in older females (b).

A similar analysis was also performed with the most complex and time-consuming measurements such as bonefree lean leg mass $(\mathrm{kg})$ and knee extensor peak torque $(\mathrm{Nm})[17,18]$. It was found that these variables were able to explain much of the peak $V^{\prime} \mathrm{O}_{2}$ variability in both males (M) and females (F). Therefore, peak $V^{\prime} \mathrm{O}_{2}\left(\mathrm{~mL} \cdot \mathrm{min}^{-1}\right)$ could be predicted as $-21.9(\mathrm{M})$ or $-11.2(\mathrm{~F}) \times$ age $(\mathrm{yrs})+$ $49.2 \times$ lean leg mass $+2329(\mathrm{M})$ or $1251(\mathrm{~F})\left(\mathrm{R}^{2}=0.890\right.$, $\mathrm{SEE}=196)$ or $-21.1(\mathrm{M})$ or $-11.5(\mathrm{~F})+1.6$ knee extensor peak torque $+2926(\mathrm{M})$ or $1725(\mathrm{~F})\left(\mathrm{R}^{2}=0.871, \mathrm{SEE}=213\right)$. Interestingly, however, when simple variables were considered in the regression analysis, leg composition and strength variables did not remain with an independent power prediction. This was largely a result of the high degree of multi-collinearity between knee extensor peak torque and height and lean leg mass with height and weight in both sexes ( $\mathrm{r}$ values ranging $0.50-0.84, \mathrm{p}<$ $0.001)$.

The direct comparison among the most previously cited published equations showed that these studies systematically overestimated the current study's observed peak $V^{\prime} \mathrm{O}_{2}$ (p<0.05; fig. 3 ). The predicted minus observed mean \pm SD values $\left(\mathrm{mL} \cdot \mathrm{min}^{-1}\right)$ in males and females were as follows: HANSEN et al. [5] $=120 \pm 245$ and $165 \pm 155$; WASSERMAN et al. [29] $=221 \pm 257$ and $225 \pm 137$ and BLACKIE et al. [9] $=364 \pm 268$ and $330 \pm 130$. On the other hand, age influenced the prediction performance of the JONES et al. [6] $(p<0.05)$ : the current authors found in females aged $>50$ yrs an underestimation of the observed values ($128 \pm 183)$ and an overestimation in males and younger females ( $121 \pm 392$ and $112 \pm 182$; fig. 3). And importantly, after the application of the PRESS method [33] in the regression equations, the authors found only a mild effect in the $\mathrm{R}$ and SEE original values (RPRESS ranging 0.0120.028 units below $\mathrm{R}$ and SEEPRESS $3-6 \mathrm{~mL} \cdot \mathrm{min}^{-1}$ above $\mathrm{SEE})$, i.e. these equations might be used on other similar samples without a significant loss in both accuracy and predictive power [33].

The GET values $\left(\mathrm{mL} \cdot \mathrm{min}^{-1}\right)$ declined with age similarly in both sexes but at a lower rate than peak $V^{\prime} \mathrm{O}_{2}$ (fig. 2). Therefore, when this parameter was expressed as percentage of peak $V^{\prime} \mathrm{O}_{2}$ higher values were found in females and older subjects (fig. 2, table 3). On the other hand, as previously demonstrated [34], the $\Delta V^{\prime} \mathrm{O}_{2} / \Delta \mathrm{WR}$ slope values $(\mathrm{X} \pm \mathrm{SD}=10.6 \pm 1.1)$ and the $V^{\prime} \mathrm{O}_{2} / \mathrm{WR}$ relationship were not influenced by sex or age $\left(V^{\prime} \mathrm{O}_{2} \mathrm{~mL} \cdot \mathrm{min}^{-1}\right)=11.1$ $\left.\times \mathrm{WR}+373, \mathrm{R}^{2}=0.854, \mathrm{SEE}=194\right)$.

\section{Prediction of cardiovascular variables}

The subjects apparently performed a maximum effort since the average value of the HR reserve was only $2.5 \%$. As expected, the absolute maximal heart rate values were reduced with age in a linear fashion in both sexes. However, for the accurate prediction of the age-related HR

Table 3. - Linear prediction equations for maximum power and cardiovascular/gas exchange responses to maximum ramp-incremental cycle ergometry in sedentary males $(M)$ and females $(F)$

\begin{tabular}{lcccccccc}
\hline Variable & Sex & Age yrs & Weight kg & Height cm & Constant & $\mathrm{R}^{2}$ & SEE & Lower 95\% CL \\
\hline Max exercise power $(\mathrm{W})$ & $\mathrm{M}$ & -1.78 & 0.65 & 1.36 & -45.4 & 0.674 & 25 & 41 \\
& $\mathrm{~F}$ & -1.19 & - & 0.96 & 28.1 & 0.714 & 14 & 23 \\
HR,max bpm & $\mathrm{M}$ & -0.87 & - & - & 211 & 0.563 & 13 & 22 \\
& $\mathrm{~F}$ & -0.88 & -0.43 & - & 239 & 0.691 & 11 & 18 \\
Max $V^{\prime} \mathrm{O}_{2} / \mathrm{HR} \mathrm{mL} \cdot$ beat $^{-1}$ & $\mathrm{M}$ & -0.09 & 0.09 & - & 10.1 & 0.452 & 2.13 & 3.5 \\
& $\mathrm{~F}$ & -0.04 & 0.08 & - & 5.1 & 0.498 & 1.16 & 1.9 \\
GET mL·min & $\mathrm{M}$ & -6.043 & 4.477 & - & 943 & 0.425 & 248 & 406 \\
GET \% Peak $V^{\prime} \mathrm{O}_{2}$ & $\mathrm{~F}$ & -3.011 & 5.654 & - & 519 & 0.408 & 185 & 303 \\
& $\mathrm{M}$ & 0.277 & - & -0.241 & 75.6 & 0.582 & 7.2 & 11.8 \\
& $\mathrm{~F}$ & 0.347 & - & - & 37.4 & 0.494 & 10.1 & 16.5 \\
\hline
\end{tabular}

see: standard ERRor of the estimate; CL: confidence limit (estimated as $1.64 \times$ sEE; Max: maximum; HR,max: maximum heart rate; bpm: beats per minute); $V^{\prime} \mathrm{O}_{2}$ : oxygen uptake; GET: gas exchange threshold. -: the independent variable was considered in question had no significant effect for the prediction of the dependent variable. 
Table 4. - Ventilatory variables in response to maximum cycle ergometry: linear prediction equations for sedentary males (M) and females (F)

\begin{tabular}{|c|c|c|c|c|c|c|c|c|}
\hline Variable & Sex & Age yrs & Weight $\mathrm{kg}$ & Height $\mathrm{cm}$ & Constant & $\mathrm{R}^{2}$ & SEE & $95 \%$ CL \\
\hline \multirow[t]{2}{*}{$V^{\prime} \mathrm{E}, \max \mathrm{L} \cdot \min ^{-1}$} & M & -0.97 & - & - & 146 & 0.379 & 21 & 35 \\
\hline & $\mathrm{F}$ & -0.55 & - & 0.58 & -1 & 0.536 & 11 & 18 \\
\hline \multirow[t]{2}{*}{$V^{\prime} \mathrm{E} / V^{\prime} \mathrm{O}_{2}{ }^{*}$} & M & 0.08 & - & - & 21.6 & 0.355 & 3.8 & 6.2 \\
\hline & $\mathrm{F}$ & 0.07 & - & - & 29.9 & 0.125 & 3.9 & 6.5 \\
\hline \multirow{2}{*}{$V^{\prime} \mathrm{E} / V^{\prime} \mathrm{CO}_{2}{ }^{*}$} & M & 0.17 & - & -0.08 & 38.6 & 0.564 & 2.8 & 4.7 \\
\hline & $\mathrm{F}$ & 0.02 & - & -0.14 & 56.8 & 0.111 & 3.2 & 5.3 \\
\hline$V^{\prime} \mathrm{E}, \max / \mathrm{MVV}$ & Both & - & - & - & $\begin{array}{c}0.68(\mathrm{M}) \\
0.58(\mathrm{~F})\end{array}$ & 0.160 & 0.12 & 0.19 \\
\hline$V^{\prime} \mathrm{E}, \max / \mathrm{MVV}^{*}$ & Both & -0.0013 & - & - & $\begin{array}{c}0.15(\mathrm{M}) \\
0.18(\mathrm{~F})\end{array}$ & 0.415 & 0.03 & 0.05 \\
\hline $\operatorname{Max} f \mathrm{rpm}$ & Both & -0.15 & - & - & 49 & 0.102 & 8 & 13 \\
\hline \multirow[t]{2}{*}{$\operatorname{Max} V \mathrm{~T} \mathrm{~mL}$} & M & -8.65 & - & 31.45 & -2450 & 0.359 & 382 & 626 \\
\hline & $\mathrm{F}$ & -10.13 & - & 17.06 & -561 & 0.427 & 282 & 462 \\
\hline \multirow[t]{2}{*}{$\operatorname{Max} f / V \mathrm{~T} \mathrm{rpm} \cdot \mathrm{L}^{-1}$} & M & - & - & -0.29 & 67.6 & 0.115 & 5.7 & 9.3 \\
\hline & $\mathrm{F}$ & - & - & -0.37 & 86.0 & 0.368 & 4.4 & 7.3 \\
\hline$V \mathrm{~T}, \max / \mathrm{VC}$ & Both & 0.001 & - & -0.002 & $\begin{array}{c}0.85(\mathrm{M}) \\
0.79(\mathrm{~F})\end{array}$ & 0.177 & 0.07 & 0.11 \\
\hline$V \mathrm{~T}, \max \mathrm{IC}$ & Both & - & - & - & $\begin{array}{c}0.70(\mathrm{M}) \\
0.66(\mathrm{~F})\end{array}$ & 0.164 & 0.09 & 0.14 \\
\hline $\operatorname{Max} V \mathrm{~T} / t \mathrm{I} \mathrm{mL} \cdot \mathrm{s}^{-1}$ & $\begin{array}{l}\mathrm{M} \\
\mathrm{F}\end{array}$ & $\begin{array}{l}-22.90 \\
-18.52\end{array}$ & - & $\begin{array}{l}21.90 \\
2219\end{array}$ & $\begin{array}{c}781 \\
-336\end{array}$ & $\begin{array}{l}0.266 \\
0.375\end{array}$ & $\begin{array}{l}752 \\
521\end{array}$ & $\begin{array}{c}1233 \\
854\end{array}$ \\
\hline
\end{tabular}

SEE: standard error of the estimate; CL: confidence limit (estimated as $1.64 \times \mathrm{SEE}$ ); $V^{\prime} \mathrm{E}$,max: maximal minute ventilation; $V^{\prime} \mathrm{O}_{2}:$ oxygen uptake; $V^{\prime} \mathrm{CO}_{2}$ : carbon dioxide production; MVV: maximal voluntary ventilation; $f$ : breathing frequency; rpm: revolutions per minute; $V$ T: tidal volume; VC: vital capacity; IC: inspiratory capacity; $t \mathrm{I}$ : inspiratory time. -: the independent variable in question had no significant effect for the prediction of the dependent variable. *: as measured at the gas exchange threshold.

reduction in females was necessary to consider weight; so that, the older and obese females had the lowest HRmax values (table 3 ). The maximum $\mathrm{O}_{2}$ pulse also reduced with age, although at a steeper rate in males (table 3); this would be expected considering the steeper decline in the peak $V^{\prime} \mathrm{O}_{2}$ values in males (fig. 2).

\section{Prediction of ventilatory and breathing pattern variables}

The overall analysis of the different aspects of the ventilatory response show that sex, age and height should be considered for accurate prediction of the reference intervals for the variables with clinical interest: a set of linear regression equations is provided in table 4. Maximum ventilation values were below $90 \%$ of the maximal theoretical values (maximum voluntary ventilation (MVV)) in all of the subjects studied. However a clear sex-effect was found: males used more of their ventilatory reserve than females, independent of age (fig. 4). Interestingly, younger females had higher ventilatory equivalents at the GET than younger males but a steeper increase with age was found in males (fig. 4).

\section{Discussion}

This study presents a comprehensive set of reference values for the clinical interpretation of ventilatory, gas exchange, pulmonary, and cardiovascular responses to ramp-incremental cycle ergometry in sedentary males and fe-males. To the authors' knowledge, this represents the first study designed specifically to determine standard maximum exercise values in which a randomization process was undertaken (table 5). Therefore, the sample evaluated is likely to be representative of the nonathletic population usually referred to clinical exercise laboratories for cardiopulmonary exercise testing.
The main results suggest that for the peak $V^{\prime} \mathrm{O}_{2}$ prediction it is important to include: sex, age, body mass and height (group I equations; table 2). A measure of regular physical activity pattern is strongly advisable based on the improvement in the residuals adjustment. The use of a detailed physical activity questionnaire [15] proved not to be more advantageous than the self-reported weekly leisure time score [16]. Although this study confirmed previous evidence that more sophisticated and time-consuming measurements, such as segmental body composition and peripheral muscular strength, had a significant relationship with the peak $V^{\prime} \mathrm{O}_{2}$, [35-37] these variables did not improve the equations' predictive power compared with the simpler and more widely-used variables.

The lower absolute age-adjusted peak $V^{\prime} \mathrm{O}_{2}$ values of the authors' population compared with those found in the European and North American studies might be related to a smaller body size, muscularity and overall oxygen transport system in a sample with a minority of Caucasian subjects. However, this is unlikely to be the case in this study: the height and body mass range of the subjects in the sample were not significantly different from those of previous reference studies [4-10]. Additionally, other potential contributory effects such as poor nutrition and anaemia were avoided as a result of the exclusion criteria. Furthermore, as cited, the data was only pooled after determining that there was no effect of ethnicity on the maximal exercise responses. On the other hand, the hypothesis that some of the individuals in the previous studies were not actually representative of their respective populations (i.e. favouring the fitter ones) cannot be excluded. Indeed, the crucial importance of evaluating a random sample was illustrated by analysis of the nonaccepted volunteers: they were younger, taller, leaner and more active than the study group. On the other hand, the 

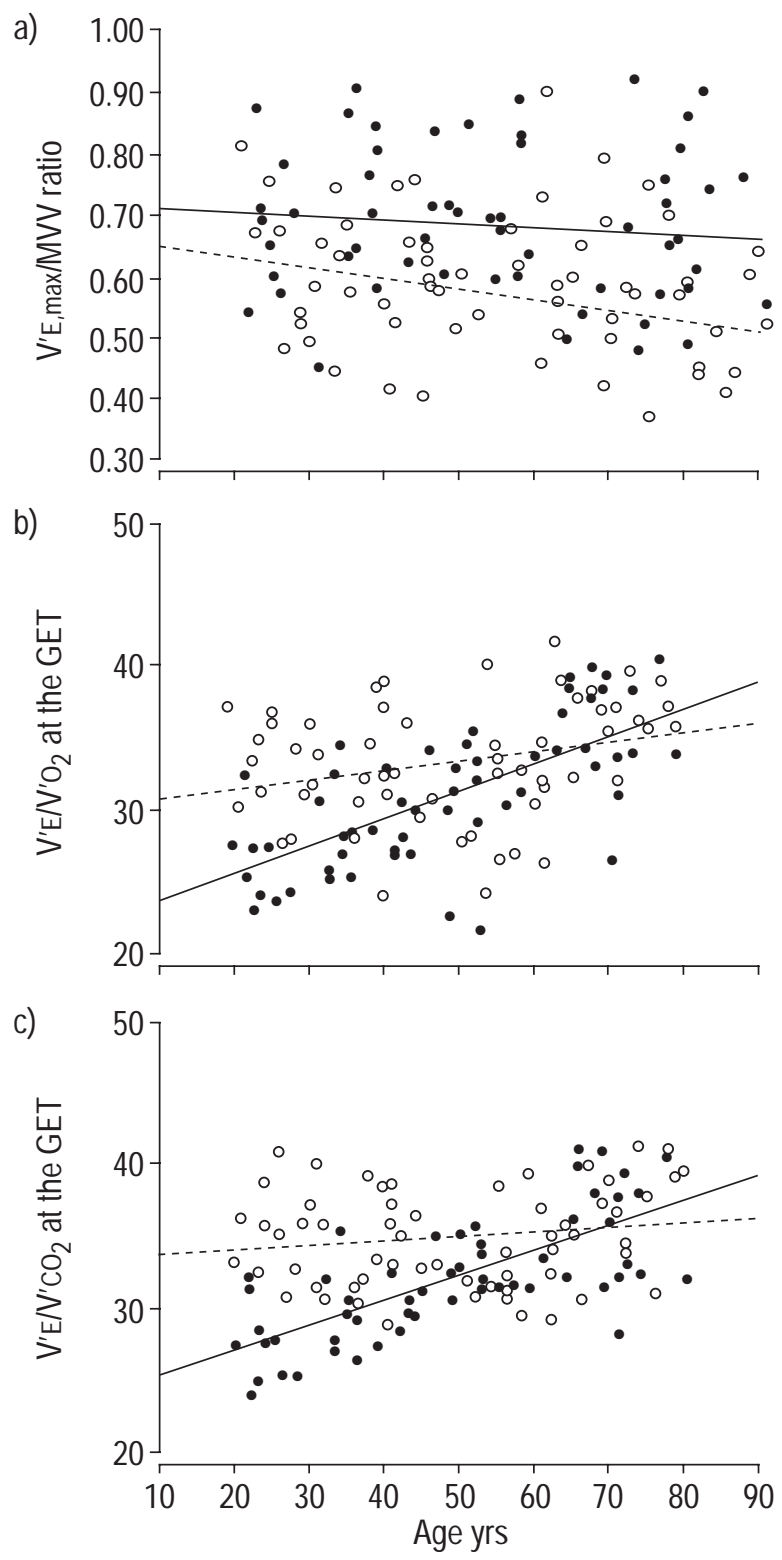

Fig. 4. - Main ventilatory responses to incremental cycle ergometry. The maximum ventilatory stress (maximum minute ventilation $\left(V^{\prime} \mathrm{E}, \max \right)$ maximum voluntary ventilation (MVV) ratio) was higher in males (O) than females $(\bigcirc)$ and no age-effect was found (a). The ventilatory equivalents for both oxygen and carbon dioxide at the gas exchange threshold (GET) increased with age, mainly in males (b and c). $V^{\prime} \mathrm{E}$ : minute ventilation; $V^{\prime} \mathrm{CO}_{2}$ : carbon dioxide production; $V^{\prime} \mathrm{O}_{2}$ : oxygen consumption.

studied sample is likely to be representative of the nontrained western population.

The reference intervals for certain variables (such as the GET and the $V^{\prime}$ E,max/MVV ratio) are important issues for the interpretation of clinical cardiopulmonary exercise testing. The authors preferred to calculate the $95 \%$ confidence limit using a clinically useful estimate [13], i.e. the predicted value $\pm 1.64 \times$ SEE. Although the high level of homoscedasticity found in the residual distribution precludes the use of a fixed "percentage of predicted", it should be noted that this approximation ignores the hyperbolic nature of the confidence interval around the regression lines, i.e. it tends to be an over-optimistic estimation of the "true" interval [32]. In this study, these limits were somewhat different from those previously recommended [5, $29,38]$, mainly with respect to the different assumptions, i.e. this study did not assume a single cut-off value. The results therefore are in concordance with those of WASSERMAN et al. [29] who suggest that sex- and age-specific cut-offs for the GET are necessary (percentage peak $V^{\prime} \mathrm{O}_{2}$ ); furthermore, they should also consider height in males (table 3 ). This seems to reflect the strong age and body-size dependence of the anaerobic component of the exercise tolerance as manifested by the steeper age-related decline for peak $V^{\prime} \mathrm{O}_{2}$ than GET (i.e. a progressively smaller difference between the gas exchange threshold and peak $V^{\prime} \mathrm{O}_{2}$; fig. 2). The reduced ventilation at maximum exercise paralleled the decline in the maximal ventilatory capacity with ageing, so that no discernible effect was evident in the $V^{\prime} \mathrm{E}, \max / \mathrm{MVV}$ ratio. On the other hand, sex had a clear effect in the ventilatory reserve; therefore, the $95 \%$ upper confidence limit for the $V^{\prime} \mathrm{E}, \max / \mathrm{MVV}$ ratio should be higher in males (fig. 4). In addition, this study presented an age- and sex-specific prediction equation for the $V^{\prime} \mathrm{E}, \max / \mathrm{MVV}$ ratio at the GET (table 4), recently reported to be a useful submaximal variable with both high positive and negative predictive values to differentiate pulmonary from cardiovascular limitation [39]. All of these findings, naturally, have important potential consequences for exercise-based diagnostic strategies.

Certain limitations of this study are worthy of mention. For example, although a metabolic calibrator was used to validate the ventilatory and gas exchange measurements [27], the "true" standard criterion was not used (timed expired gas collection). Furthermore, the cycle ergometer was not directly calibrated against a torquemeter. It is believed, however, that this does not present a concern in this study, as both the steady-state $V^{\prime} \mathrm{O}_{2}$ at $25 \mathrm{~W}$ and the slope of the $V^{\prime} \mathrm{O}_{2}$-work rate relationship during the ramp were consistent with previous validation studies $[29,34$, 40]. The authors also considered the minimum sample size needed, with an even distribution of age and anthropometric characteristics. This sample size, larger than two of the most widely-cited sources of reference values $[5,6]$, was sufficient to make the error of the estimated population predicted values acceptable for clinical purposes. That is, the sex-specific predicted value (group I equations; table 2), for the "average" male and female subject is, respectively, 2,085 and 1,338 $\mathrm{mL} \cdot \mathrm{min}^{-1}$ (upper and lower $95 \%$ confidence limits of 2,614-1,556 and 1,604-1,072) with an SEE of 270 (M) and $136(\mathrm{~F})$ $\mathrm{mL} \cdot \mathrm{min}^{-1}$. This allows the accuracy of the equations be estimated as $17.3-10.3 \%(\mathrm{M})$ and $12.6-8.4 \%(\mathrm{~F})$ (i.e. SEE/ lower or upper $95 \%$ confidence limit $\times 100)$ [10]. Hence, the simplest set of equations is expected to predict, on average, peak $V^{\prime} \mathrm{O}_{2}$ to within $15 \%(\mathrm{M})$ and $10 \%(\mathrm{~F})$ of the true value for 95 out of every 100 sedentary subjects, with anthropometric and demographic characteristics similar to those of the current subjects. However, it is important that the predictive accuracy of this frame of reference should also be tested in other sedentary populations.

In summary, the authors have presented, what they believe to be, the first set of predictive equations for the gas exchange, ventilatory and cardiovascular variables during maximum cycle ergometry obtained in a randomized sample. Interestingly, the most widely-used predictive equations for peak oxygen uptake typically overestimated 
Table 5. - Main characteristics of the most-cited reference studies for maximum exercise variables and the present study

\begin{tabular}{|c|c|c|c|c|c|c|c|c|}
\hline First author [Ref.] & $\begin{array}{l}\text { Sample } \\
\text { size }\end{array}$ & $\begin{array}{l}\text { Age } \\
\text { yrs }\end{array}$ & $\begin{array}{l}\text { Population } \\
\text { sample }\end{array}$ & Study design & $\begin{array}{l}\text { Sample } \\
\text { selection }\end{array}$ & $\begin{array}{l}\text { Modality } \\
\text { exercise }\end{array}$ & $V^{\prime} \mathrm{O}_{2}, \max$ & Averaging \\
\hline BRUCE et al. [4]** & $\begin{array}{l}151 \mathrm{M} \\
144 \mathrm{~F}\end{array}$ & $29-73$ & General population & Prospective* & Volunteered & Treadmill & Douglas bag & $60 \mathrm{~s}$ \\
\hline HANSEN et al. [5] $]^{* *}$ & $77 \mathrm{M}$ & $34-74$ & Shipyard workers & Retrospective & Referred & Cycle & Breath-by-breath & $20 \mathrm{~s}$ \\
\hline JONES et al. [6] & $\begin{array}{l}50 \mathrm{M} \\
50 \mathrm{~F}\end{array}$ & $15-71$ & $\begin{array}{l}\text { University/General } \\
\text { population }\end{array}$ & Prospective* & $\begin{array}{l}\text { Volunteered } \\
\text { Selected }\end{array}$ & Cycle & Mixing chamber & $15 \mathrm{~s}$ \\
\hline VogeL et al. [8] & $\begin{array}{l}1514 \mathrm{M} \\
375 \mathrm{~F}\end{array}$ & $17-55$ & Soldiers & Retrospective & $\begin{array}{c}\text { Referred } \\
\text { Volunteered }\end{array}$ & Treadmill & Douglas bag & $60 \mathrm{~s}$ \\
\hline BLACKIE et al. [9] & $\begin{array}{l}47 \mathrm{M} \\
81 \mathrm{~F}\end{array}$ & $55-80$ & $\begin{array}{l}\text { Hospital/Senior } \\
\text { centres }\end{array}$ & Prospective* & Volunteered & Cycle & Mixing chamber & $30 \mathrm{~s}$ \\
\hline STORER et al. [10] & $\begin{array}{l}115 \mathrm{M} \\
116 \mathrm{~F}\end{array}$ & $20-70$ & General population & Prospective* & "Recruited" & Cycle & $\begin{array}{l}\text { Mixing chamber/ } \\
\text { Breath-by-breath }\end{array}$ & $30 \mathrm{~s}$ \\
\hline \multirow{2}{*}{$\begin{array}{l}\text { INBAR et al. [11] } \\
\text { Present study }\end{array}$} & $1424 \mathrm{M}$ & $20-70$ & General population & Retrospective & Referred & Treadmill & Breath-by-breath & $30 \mathrm{~s}$ \\
\hline & $\begin{array}{l}60 \mathrm{M} \\
60 \mathrm{~F}\end{array}$ & $20-80^{*}$ & $\begin{array}{l}\text { University/General } \\
\text { population }\end{array}$ & Prospective* & Randomized* & Cycle & Breath-by-breath & $15 \mathrm{~s}$ \\
\hline
\end{tabular}

*: aspects of particular methodological interest; **: WASSERMAN et al. [29] prediction equations for maximum oxygen uptake are based on these studies.

the observed values: these findings are most likely to be related to the evaluation of nonrandomized subjects in previous studies. In addition, it is suggested that $95 \%$ confidence limits of the prediction should be used as an estimation of the reference intervals rather than of a single cut-off value, as was the case in most of the previously published reference values.

Acknowledgements. The authors thank C. Peres (Universidade Federal de Sao Paulo-Escola Paulista de Medicina (UNIFESP-EPM)) for help with the statistical analysis; L. Hashimoto, M. Hashimoto, D. Siquieroli, M. Tonini and V. Rigoni from the Pulmonary Function and Exercise Laboratories of the Pulmonary Division (UNIFESP-EPM), for their technical support; M. DiPietro for excellent work in designing the data storage software system (CPX Data); the technical staff of the LAFIREX, Exercise Laboratory of the Department of Physiology (UNIFESP-EPM), for performing the isokinetic dynamometry; the Endocrinology Division of UNIFESP-EPM for providing the dual energy $x$-ray absorptiometry (DEXA) system, and principally all of the participants for their efforts and co-operation.

\section{References}

1. Zeballos RJ, Weisman IM. Behind the scenes of cardiopulmonary exercise testing. Clin Chest Med 1994; 15: 193-204.

2. Martinez FJ, Stanopoulos I, Acero P, Becker FS, Pickering R, Beamis JF. Graded comprehensive cardiopulmonary exercise testing in the evaluation of dyspnea unexplained by routine evaluation. Chest 1994; 105: 168174.

3. Sue DY. Exercise testing in the evaluation of impairment and disability. Clin Chest Med 1994; 15: 369-387.

4. Bruce RA, Kusurni F, Hosner D. Maximal oxygen intake and nomographic assessment of functional aerobic impairment in cardiovascular disease. Am Heart $J$ 1973; 85: $546-562$.

5. Hansen JE, Sue DY, Wasserman K. Predicted values for clinical exercise testing. Am Rev Respir Dis 1984; 129 (Suppl. 2): S49-S55.

6. Jones NL, Makrides L, Hitchcock Q, Chypchar T, McCartney N. Normal standards for an incremental prog- ressive cycle ergometer test. Am Rev Respir Dis 1985; 131: 700-708.

7. Jones NL, Summers E, Killian KJ. Influence of age and stature on exercise capacity during incremental cycle ergometry in men and women. Am Rev Respir Dis 1986; 140: $1373-1380$

8. Vogel JA, Patton M, Mello RP, Daniels WL. An analysis of aerobic capacity in a large United States population. $J$ Appl Physiol 1986; 60: 494-500.

9. Blackie SP, Fairbarn MS, McElvaney GN, Morrison NJ, Wilcox PG, Pardy RL. Prediction of maximal oxygen uptake and power during cycle ergometry in subjects older than 55 years of age. Am Rev Respir Dis 1989; 139: 1424-1429.

10. Storer TW, Davis JA, Caiozzo VJ. Accurate prediction of $V^{\prime} \mathrm{O}_{2}$ max in cycle ergometry. Med Sci Sports Exerc 1990; 22: 704-712.

11. Inbar O, Oren A, Scheinowitz M, Rotstein A, Dlin R, Casaburi R. Normal cardiorespiratory responses during incremental exercise in 20-to-70-yr-old men. Med Sci Sports Exerc 1994; 26: 538-546.

12. Davis JA, Storer TW, Caiozzo VJ. Prediction of normal values for lactate threshold estimated by gas exchange in men and women. Eur J Appl Physiol 1997; 75: 157-164.

13. Altman DG. Practical Statistics for Medical Research. London: Chapman \& Hall, 1996.

14. World Health Organization. WHO Expert Commitee on Physical Status: Interpretation of Anthropometry. Geneve: WHO, 1995.

15. Baecke JAH, Burema J, Frijters JER. A short questionnaire for the measurement of habitual physical activity in epidemiological studies. Am J Clin Nutr 1982; 36: 936-942.

16. Saltin B, Grimby G. Physiological analysis of middleaged and old former athletes. Circulation 1968; 38: 11041115.

17. Lukaski HC. Soft tissue composition and bone mineral status: evaluation by dual energy X-ray absorptiometry. $J$ Nutr 1993; 123: 438-442.

18. Gleeson NP, Mercer TH. The utility of isokinetic dynamometry in the assessment of human muscle function. Sports Med 1996; 21: 18-34.

19. American Thoracic Society. Lung function testing. Selection of reference values and interpretative strategies. Am Rev Respir Dis 1991; 144: 1202-1218. 
20. Wilson SH, Cooke NT, Edwards RHT, Spiro SG. Predicted normal values for maximal respiratory pressures in caucasian adults and children. Thorax 1984; 39: $535-538$.

21. Stocks J, Quanjer PhH. ATS/ERS Workshop on lung volume measurements. Reference values for residual volume, functional residual capacity and total lung capacity. Eur Respir J 1995; 8: 492-506.

22. Cotes JE, Chinn DJ, Quanjer PH, Roca J, Yernault JC. Standardization of the measurement of transfer factor (diffusing capacity). Report working party standardization of lung function tests. European community for steel and coal. Eur Respir J 1993; 16: S41-S52.

23. Dumin JV, Womersley J. The relationship between skinfolds thickness and body fat in adults of middle age. J Physiol (Lond) 1969; 200: 105P-106P.

24. Jensen MD, Kanaley JA, Roust LR, et al. Assessment of body composition with use of dual-energy x-ray absorptiometry: evaluation and comparison with other methods. Mayo Clin Proc 1993; 68: 867-873.

25. Madsen OR, Lauridsen UB, Hankopp A, Sorensen OH. Muscle strength and soft tissue composition as measured by dual energy X-ray absorptiometry in women aged 18 87 years. Eur J Appl Physiol 1997; 75: 239-245.

26. Beaver WL, Lamarra N, Wasserman K. Breath-by-breath measurement of true alveolar gas exchange. J Appl Physiol 1981; 51: 1662-1675.

27. Huszczuk A, Whipp BJ, Wasserman K. A respiratory gas exchange simulator for routine calibration in metabolic studies. Eur Respir J 1990; 3: 465-468.

28. Buchfuhrer MJ, Hansen JE, Robinson TE, Sue DY, Wasserman K, Whipp BJ. Optimizing the exercise protocol for cardiopulmonary assessment. J Appl Physiol 1983; 55: 1558-1564.

29. Wasserman K, Hansen JE, Sue DY, Casaburi R, Whipp
BL. Principles of Exercise Testing and Interpretation. 2nd Edn. Philadelphia; Lea \& Febiger, 1994; p. 479.

30. Beaver WL, Wasserman K, Whipp BJ. A new method for detecting the anaerobic threshold by gas exchange. $J$ Appl Physiol 1986; 60: 2020-2027.

31. Reinhard V, Muller PH, Schmulling R-M. Determination of anaerobic threshold by the ventilation equivalent in normal individuals. Respiration 1979; 38: 36-42.

32. Kleinbaum DG, Kupper LL, Mufler AE. Applied Regression Analysis and other Multivariable Methods. 2nd Edn. Belmont, CA, USA: Duxbury Press, 1988.

33. Holiday DB, Ballard JE, McKeown BC. PRESS-related statistics: regression tools for cross-validation and case diagnostics. Med Sci Sports Exerc 1995; 27: 612-620.

34. Wasserman K, Whipp BJ. Exercise physiology in health and disease. Am Rev Respir Dis 1975; 112: 219-249.

35. Toth MJ, Gardner AW, Ades PA, Howard DB, Poehlman ET. Contribution of body composition and physical activity to age-related decline in peak $V^{\prime} \mathrm{O}_{2}$ in men and women. J Appl Physiol 1993; 77: 647-652.

36. Proctor DN, Joyner MJ. Skeletal muscle mass and the reduction of $V^{\prime} \mathrm{O}_{2}$ max in trained older subjects. $J \mathrm{Appl}$ Physiol 1997; 82: 1411-1415.

37. Pollock ML, Mengelkoch U, Graves JE, et al. Twentyyear follow-up of aerobic power and body composition of older track athletes. J Appl Physiol 1997; 82: 1508-1516.

38. Jones NL. Clinical Exercise Testing. 4th Edn. Philadelphia: Saunders, 1997.

39. Medoff BD, Oelberg DA, Kandrek DJ, Systrom DM. Breathing reserve at the lactate threshold to differentiate a pulmonary mechanical from cardiovascular limitation to exercise. Chest 1998; 113: 913-918.

40. Whipp BJ, Davis JA, Torres F, Wasserman K. A test to determine parameters of aerobic function during exercise. J Appl Physiol 1981; 50: 217-221. 